\title{
EDITORIAL
}

\section{Careful Research Needed}

\author{
The Use of Deep Brain Stimulation in Psychiatric IIInesses
}

Urban Wiesing

An editorial to accompany the article "Deep Brain Stimulation for Psychiatric Disorders" by Jens Kuhn, et al., in this issue of Deutsches Ärzteblatt International

Institut für Ethik und Geschichte der Medizin, Universität
D eep brain stimulation (DBS) has become well established in recent years as a treatment for Parkinson's disease. As Kuhn et al. describe in their review article (1), the efficacy and safety of DBS for the treatment of psychiatric diseases are a current focus of research. Not a few people view this development with concern, and the reasons are evident. DBS is a direct intrusion into the human brain, the very organ that is most intimately connected to the human personality. Such interventions easily give rise to futuristic fantasies about interactions between man and machine. Furthermore, it might appear dubious that highly complex phenomena such as psychiatric diseases are supposed to be remediable with a circumscribed, local treatment. Not least, poor experiences from an earlier era of brain surgery give reason to worry: Until now, surgery for psychiatric diseases has always turned out to be on the wrong track, as its undesired effects have always outweighed its benefits to an unacceptable extent.

\section{Multiple causes for concern}

Deep brain stimulation arouses concern regarding each of three areas: the therapeutic approach itself, its possible undesired effects, and the future development of psychosurgery. How serious are these concerns?

The idea that highly complex psychiatric diseases affecting the human personality might be successfully treated - even over the long term-with local stimulation in the brain may well seem strange in itself. Is not this notion too mechanistic, too reductionistic, too localistic? The objection is plausible, perhaps, on a theoretical level. But should there be no further study of a potentially therapeutic approach for this reason alone? Of course, the overall therapeutic strategy of any treatment needs to be well thought out in advance, yet, as elsewhere in clinical medicine, success for the patient is what counts in the end. If it turns out that psychiatric diseases can be effectively treated with local stimulation, then any theoretical doubts are of secondary interest (2). Science, however, has yet to determine whether deep brain stimulation is indeed effective against psychiatric diseases, and, if so, what disease states should be so treated, and what target sites should be stimulated. Such determinations can only be made by clinical testing, which necessarily carries risks.

This brings us to the second category of concern. There is no certainty that DBS will not have undesired effects, including on the patient's personality; one can be still less confident on this matter when the treatment is being used for the first time. Although, as Kuhn et al. report, the initial experience has been favorable, it is self-evidently the case that long-term adverse effects will only be revealed by long-term observation. Might this be a reason to stop any further testing of this therapeutic approach?

DBS is not the only area where medicine faces questions of this type. The most important data on the effectiveness and safety of medical treatments can only be obtained by testing on human beings; testing on animals and in vitro can only complement, but never replace clinical research. All human experimentation carries a risk of injury to the patient, and taking such risks actually runs counter to the physician's obligation to do no harm. The paradox is that physicians are supposed to use only scientifically tested treatments, but, strictly speaking, are not allowed to test a treatment scientifically (3).

To provide a way out of this dilemma, a broad consensus has developed that research on human beings is fundamentally legitimate, as long as certain strict criteria are met: The rights of study participants must be respected, in particular through the obtaining of informed consent; the researchers, and the research project, must satisfy strict requirements; and the risk to the study participants must be kept as low as possible.

\section{Arguments in favor of testing}

Are there any good reasons why deep brain stimulation for the treatment of psychiatric diseases should not even be tested, in the light of currently prevailing standards of ethics in medical research? Hardly. Experience to date has shown that, when deep brain stimulation is used to treat Parkinson's disease, its undesired effects (aside from those of the surgical procedure itself) are generally acceptable, as they are outweighed by the patient's improved mobility and quality of life, and are also reversible (4). As for the potential risk of adverse effects on the patient's personality, it should be remembered that such risks are also present in therapeutic trials of psychotropic drugs. Research on DBS has already led to effective treatment for some conditions that were previously intractable, and the clinical testing of DBS for psychiatric diseases is restricted, at least for the time being, to intractable disease states. If the risk were considered unacceptable, then all research on this 
method would have to be stopped, despite the encouraging initial results.

Fears remain about future developments in brain surgery and in the interaction between man and machine. One can certainly imagine interventions in the brain that would violate human dignity, particularly if they were designed to manipulate the patient's personality and autonomy. But do such fears really justify a moratorium on further research into DBS for psychiatric diseases? No. If they did, then it would have been equally wrong even to begin clinical testing of DBS to treat other diseases.

\section{Prudence in research}

These concerns do not, in the end, suffice to justify stopping research on DBS for psychiatric diseases (5), but they do remind us to act prudently. Patients must be completely informed. Research efforts should be coordinated to prevent unnecessary duplication. All findings - not just the positive ones! - must be published, so that further studies can be designed on the basis of maximal available data. All experiments must incorporate strict safety measures to keep risks as low as possible. Therapeutic fads involving the hasty application of untested methods must be avoided. There is no acceptable alternative to these requirements, and, even when they are met, DBS research still poses a challenge to the researchers' prudence and competence.
Conflict of interest statement

The author declares that he has no conflict of interest as defined by the guidelines of the International Committee of Medical Journal Editors.

Translated from the original German by Ethan Taub, M.D.

\section{REFERENCES}

1. Kuhn J, Gründler T, Lenartz D, et al: Deep Brain Stimulation for Psychiatric Disorders. Dtsch Arztebl Int 2010; 107 (7): 105-113

2. Wiesing U: Wer heilt, hat Recht? Über Pragmatik und Pluralität in der Medizin. Stuttgart: Schattauer 2004.

3. Toellner R: Problemgeschichte: Entstehung der Ethik-Kommissionen. In: Toellner R (ed.): Die Ethik-Kommission in der Medizin. Stuttgart New York: Gustav Fischer 1990; 3-18.

4. Weaver FM, Follett K, Stern M, et al.: Bilateral deep brain stimulation vs. best medical therapy for patients with advanced parkinson disease. A randomized controlled trial. JAMA 2009; 301: 63-73.

5. Clausen J: Man, machine and in between. Nature 2009; 457 1080-1.

\section{Corresponding autho}

Prof. Dr. med. Dr. phil. Urban Wiesing

Universität Tübingen

Institut für Ethik und Geschichte der Medizin

Gartenstr. 47

72074 Tübingen, Germany

urban.wiesing@uni-tuebingen.de

\section{Gite this as: Dtsch Arztebl Int 2010; 107(7): 103-4} DOI: 10.3238/arztebl.2010.0103 